study were double those in control animals given similar doses of MTX alone. We found that this difference was maintained in man for at least 24 hours.

Because the inhibitory effect of probenecid on tubular excretion of MTX varies from patient to patient ${ }^{9}$ its effect on prolonging high serum concentrations of the drug will also vary and consequently increase the risk of MTX toxicity. It is therefore important to measure the time taken for MTX to be eliminated. Probenecid also induces changes in the clearance of other acidic drugs, such as ampicillin, ${ }^{10}$ indomethacin, ${ }^{9}$ and frusemide, ${ }^{11}$ which share a common excretory route, so these and other acidic drugs can probably influence MTX excretion. Indeed, in one patient (not in this trial) examined by us and prescribed aspirin and papaveretum tablets during treatment with MTX the elimination half life of MTX was 9.6 hours. Thus to avert toxicity it is important to monitor serum concentrations whenever probenecid or any other drug capable of delaying the excretion of MTX is given concomitantly with MTX. With more recent radioimmunoassay techniques, such as those that use ${ }^{75} \mathrm{Se}$-labelled $\mathrm{MTX},{ }^{12}$ results may be obtained within two to three hours of collecting the blood.

It has been suggested that the minimum effective therapeutic serum concentration of MTX is $1 \mu \mathrm{mol} / 1(45 \mu \mathrm{g} / 100 \mathrm{ml}){ }^{8}$ This was exceeded for as long a period after a single intravenous bolus injection of MTX and some form of probenecid as during and after a constant intravenous infusion. As the administration of probenecid and MTX by injection is much more convenient we suggest that it may be used to reduce the time spent in hospital by a patient receiving MTX treatment. In addition, patients with a normal glomerular filtration rate may be prescribed MTX with probenecid in order to attain higher serum
MTX concentrations than would be attained with similar doses of MTX alone. Alternatively, a smaller dose of MTX may be administered with probenecid to achieve the same serum concentrations as when MTX is given alone. It should therefore be possible to reduce the cost of treatment with MTX without decreasing its efficacy.

We thank the medical and nursing staff of the radiotherapy department for their helpful co-operation during these studies. We are grateful for the financial support of the Leukaemia Research Fund.

\section{References}

${ }^{1}$ Frei, E, et al, New England fournal of Medicine, 1975, 292, 846.

2 Shapiro, W R, Young, D F, and Mehta, B M, New England fournal of Medicine, 1975, 293, 161.

${ }^{3}$ Liegler, D G, et al, Clinical Pharmacology and Therapeutics, 1969, 10, 849.

${ }^{4}$ Bourke, R S, et al, Cancer Research, 1975, 35, 110.

5 Aherne, G W, Piall, E, and Marks, V, British fournal of Cancer, 1977, 36, 608.

${ }^{6}$ Henderson, E S, Adamson, R H, and Oliverio, V T, Cancer Research, 1965, 25, 1018.

7 Huffman, D H, et al, Clinical Pharmacology and Therapeutics, 1973, 14, 572.

${ }^{8}$ Hrynuik, W H, and Bertino, J R, Fournal of Clinical Investigation, 1969, 48, 2140.

${ }^{9}$ Skeith, M D, Simkin, P A, and Healey, L A, Clinical Pharmacology and Therapeutics, 1967, 9, 89.

${ }^{10}$ Eickhoff, T C, Kislak, J W, and Finland, M, American fournal of the Medical Sciences, 1965, 249, 163.

11 Homeida, M, Roberts, C, and Branch, R A, Clinical Pharmacology and Therapeutics, 1977, 22, 402.

12 Aherne, G W, Piall, E, and Marks, V. Submitted for publication.

(Accepted 21 February 1978)

\title{
Early results of closed partial meniscectomy
}

\author{
DAVID J DANDY
}

British Medical fournal, 1978, 1, 1099-1101

\section{Summary and conclusions}

Thirty patients underwent partial meniscectomy through two puncture incisions by a closed technique under arthroscopic control. "Bucket-handle" fragments were removed from 17 knees, and flaps or tags from the remainder. The mean stay in hospital after operation was 1.3 days and the mean time for return to working fitness was 10.5 days. There were no serious complications. Further study of the long-term results of this technique is needed.

\section{Introduction}

Displaced segments of damaged meniscus commonly cause internal derangement of the knee, and, together with the operation of meniscectomy for their relief, give rise to much disability. Morbidity after meniscectomy largely results from

\footnotetext{
Department of Orthopaedic Surgery, Newmarket General Hospital, Newmarket, Suffolk

DAVID J DANDY, FRCS, consultant surgeon
}

surgical damage to the skin, joint capsule, subcutaneous tissue, and synovium, for the meniscus itself is insensitive and avascular and in theory could be cut or trimmed without irritating the joint. Damage to the soft tissues may be reduced by use of a closed technique, whereby meniscal fragments are removed through two puncture incisions, each about $6 \mathrm{~mm}$ long. The early results of this technique in 30 patients are presented.

\section{Patients and methods}

Technique-All joints were examined arthroscopically, particular attention being paid to the meniscus. Probing needles passed beneath the meniscus along the joint line were used to lift the meniscus so that its inferior surface could be examined and the integrity of the meniscosynovial junction assessed. When the anatomy of the meniscal lesion had been determined, operating instruments were inserted via the anteromedial route, the mobile meniscal fragments being removed and the meniscus trimmed until an intact, even rim remained. No attempt was made to remove the intact and undamaged parts of the meniscus. The two wounds were closed with one stitch each and a light dressing of plaster wool and crêpe bandage was applied. All patients received physiotherapy before discharge, and a nonsteroidal anti-inflammatory drug (ketoprofen $50 \mathrm{mg}$ thrice daily) was prescribed for 10-14 days after operation.

Patients-Twenty-seven men and three women (mean age 33.7 years; range 18-57) underwent operation. Fifteen patients worked in sedentary occupations (executive, student, draughtsman) and 15 in strenuous occupations (labourer, farmer, waiter). All had symptoms 
of mechanical derangement of the knee, such as clicking, a sensation of something moving inside the knee, or recurring locking and jamming of the joint. Ten knees, all with bucket-handle tears, were locked at the time of operation.

Type of lesion-Seventeen patients had longitudinal (bucket-handle) tears and 13 had flaps or tags. Four patients also had an old rupture of the anterior cruciate ligament with anterolateral rotatory instability ("pivot-shift phenomenon"). Eight patients had early degenerative changes in the articular cartilage of the femoral condyle adjacent to the damaged meniscus. There were 22 damaged medial menisci and eight lateral.

\section{Results}

Progress after operation-Progress was a little slower than after arthroscopy alone. All patients were able to raise the leg straight on the day of operation, and could flex the knee to $90^{\circ}$ and walk with full weight bearing on the day of operation or the following day. A small effusion lasting three to four days was usual. A trace of fluid remained in about half the knees when the stitches were removed 10-14 days after operation, but none had an obvious effusion. Thickening and tenderness around the wounds on either side of the tibial tendon were usual, and made full extension uncomfortable for the first week after operation in some patients. Medial wounds took longer to settle than lateral. Crutches or other walking aids were not needed after the first week. The mean stay in hospital after operation was 1.3 days (range $0-4$ ). The mean time for return to work was 6.6 days (range 2-27) for patients in sedentary occupations and 16.5 days (range 6-40) for those in strenuous occupations. The overall mean time for return to work was 10.5 days (range 2-40). Recovery was slower in patients with degenerative changes in the articular cartilage, and patients with ligament injuries needed more physiotherapy (table I).

TABLE I-Influence of type of lesion on recovery after closed partial meniscectomy

\begin{tabular}{|c|c|c|c|c|c|}
\hline & ype of lesion: & $\begin{array}{l}\text { Damaged } \\
\text { meniscus } \\
\text { only }\end{array}$ & $\begin{array}{l}\text { Damaged } \\
\text { meniscus } \\
\text { and } \\
\text { osteo- } \\
\text { arthritis }\end{array}$ & $\begin{array}{l}\text { Damaged } \\
\text { meniscus } \\
\text { and } \\
\text { ruptured } \\
\text { ligament }\end{array}$ & $\begin{array}{l}\text { Total } \\
\text { group }\end{array}$ \\
\hline No of patie & discharge & 18 & 8 & 4 & 30 \\
\hline $\begin{array}{l}\text { Mean days } \\
\text { (range) }\end{array}$ & discharge & $1(0-2)$ & $1.75(1-4)$ & $1.25(1-2)$ & $1 \cdot 3(0-4)$ \\
\hline $\begin{array}{l}\text { Mean days } \\
\text { to return }\end{array}$ & $\left\{\begin{array}{c}\text { Strenuous } \\
\text { occupations }\end{array}\right.$ & $9 \cdot 4(6-19)$ & $23 \cdot 2(14-40)$ & $11 \cdot 7(7-18)$ & $14.5(6-40)$ \\
\hline to work & Sedentary & $5 \cdot 5(2-10)$ & $11 \cdot 3(2-27)$ & Los & $6 \cdot 6(2-27)$ \\
\hline \multicolumn{2}{|c|}{$\begin{array}{l}\text { Mean No of physiotherapy } \\
\text { sessions }\end{array}$} & $\begin{array}{c}3.5(2-10) \\
0.5\end{array}$ & $4 \cdot 25$ & 3.75 & $\begin{array}{c}0.0(2-21) \\
1.9\end{array}$ \\
\hline
\end{tabular}

Physiotherapy-Ten patients attended for physiotherapy after leaving hospital, requiring an average of 5.7 treatments each (range $2-16$ ) for a mean of 16.5 days (range $7-45$ ). The remaining 20 patients needed no outpatient physiotherapy.

Duration of operation-The mean duration of operation (from the first incision to skin closure) was 43 minutes (range 10-90). Buckethandle fragments took longer to remove (mean 49 minutes; range 19-90) than flaps or tags (mean 35 minutes; range 10-75). As the instruments were developed and experience gained, the operating time tended to diminish.

Relief of symptoms-Symptoms of mechanical derangement were relieved in all patients, but symptoms of discomfort after use were unaffected in patients with degenerative changes in the articular cartilage. The mean interval between operation and review was $20 \cdot 4$ weeks (range 8-86). All patients were clinically stable at the time of review.

Complications-One patient developed a discharge of clear fluid from the medial wound on the ninth postoperative day. It was thought that he might have developed a synovial fistula, and the knee was immobilised in plaster. After seven days the cast was removed and the wound found to be dry. His progress was uninterrupted thereafter, and he was fit enough to return to work on the 27 th postoperative day. The discharge may well have been irrigation fluid that had leaked into the subcutaneous tissues and not synovial fluid. Another patient, a rugby player, developed thickening of the soft tissues around the medial wound between 18 and 28 days after operation, which caused him to withdraw from his university team until the swelling had settled.

\section{Discussion}

The problems of rehabilitation and recovery after meniscectomy largely result from the surgical approach to the meniscus and the inevitable surgical damage to the synovium, capsule, and soft tissues around the knee. The technique of closed meniscectomy is essentially a different surgical approach rather than a different operation, and the rapid recovery after operation may be attributed to the reduction in the size of the wounds needed for access to the meniscus. Other reports of rehabilitation after meniscectomy refer to periods of incapacity ranging from 38 to 90 days $^{1-x}$ (table II), and the ability of the patients reported here to return to work in an average time of 10.5 days is encouraging. This rapid recovery probably benefits ordinary people most, by allowing them to return to work without delay, though it also enables younger patients to return to active sport within one or two weeks of operation.

TABLE II-Mean time to return to work after meniscectomy (previous series) and closed partial meniscectomy (present series)

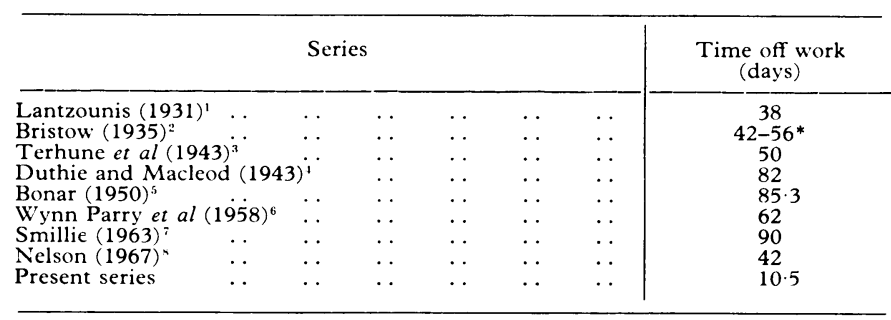

*Range.

Partial meniscectomy has been controversial for many years, but considerable evidence ${ }^{910}$ suggests that removing the dislocated bucket-handle fragment alone gives better immediate and long-term results than total meniscectomy. It is difficult to find any support for the contention that total meniscectomy is preferable to partial meniscectomy. The technique is not new. Bucket-handle fragments of meniscus were removed by Dr R W Jackson of Toronto in 1970, and the operation has been done in suitable cases since. The development of new instruments and greater familiarity with the arthroscope allow meniscal fragments to be removed by the closed technique in almost every case in which meniscectomy is indicated. The operation is difficult, tedious, often protracted, and should be attempted only by surgeons who have confidence in their arthroscopic technique.

This report deals with the immediate results of operation and with the time taken for return to normal working fitness. Since there is no important difference between closed partial meniscectomy and the orthodox open procedure apart from that of surgical approach, there is no reason to suppose that the long-term results will be any worse. A long-term study is needed to investigate this, and such a study is in progress.

I thank the staff of the operating theatres at Newmarket General Hospital for their patience during the development of this technique.

\section{References}

1 Lantzounis, L A, Surgery, Gynecology and Obstetrics, 1931, 53, 182.

2 Bristow, W, Fournal of Bone and foint Surgery, 1935, 17, 413.

3 Terhune, S R, et al, fournal of Bone and foint Surgery, 1943, 25, 663.

${ }^{4}$ Duthie, J J R, and Macleod, J G, Lancet, 1943, 1, 97.

"Bonar, A A, Glasgow Medical fournal, 1885, 31, 197

${ }^{6}$ Wynn Parry, C B, Nicholls, P J R, and Lewis, N R, Annals of Physical Medicine, 1958, 4, 201

' Smillie, I S, Injuries of the Knee foint, 3rd edn. Edinburgh, I.ivingstone, 1963.

${ }^{8}$ Nelson, M A, Annals of Physical Medicine, 1968, 9, 282.

9 Tapper, E M, and Hoover, N W, Fournal of Bone and foint Surgery, 1969 , 51A, 517.

${ }^{10}$ McGinty, J B, Geuss, L F, and Marvin, R A, fournal of Bone and Foint Surgery, 1977, 59A, 163

(Accepted 24 February 1978)

.

(a)

.
定

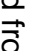

